\title{
Experiment of Input Parameters on Abrasive Water Jet Machining
}

\author{
Nikhil Rai ${ }^{1}$, Keshav Kumar Jha ${ }^{2}$ \\ ${ }^{1,2}$ Department of Mechanical Engineering , KCC Institute of Technology and Managemnt, Gr. Noida, UP,INDIA
}

\begin{abstract}
This analysis looks at the impact of modifying the coarse water jet wounding limitations on the disorder of the work piece's superficial layer. Air Jet for Abrasiveness The aerospace industry mostly uses machining to remove high-métier components and additional composites. The majority of his uses are in the machining of a gas turbines, engines, spacecraft, atomic reactors, and pumps, among other things. Rough waterjet machining is a new machining technique in which materials a is removed by abrasion. A high-velocity watercourse of abrasive subdivisions combined through purified water is directed at the work superficial. The current research focuses on the experimental investigation and assessment of abrasive $\mathrm{H}_{2} \mathrm{O}$ jet machining procedure using reaction surface technique to assess the technical factors influencing the machining efficiency of CFRP laminate. Kerf candle, delamination, material elimination rate, and superficial roughness were found to be affected by standoff coldness, feedstuff rate, and jet strain. The material connected parameter, location of fiber, has been also found to touch the machining performance. Using Taguchi's principle, Design of Experimentations are used to determine the impact of process strictures on optimal environment. To determine the best conditions, a series of tests are carried out. Method parameter optimization is expected. To verify the desired degree of Processes parameter prediction, a conformation experiment is carried out.
\end{abstract}

Keywords: Water Jet Machining (WJM), Abrasive Particle, Taguchi Principle

\section{INTRODUCTION}

In US, water jets were first used in 1970s and were only used for washing. New applications emerged as the technology advanced to incorporate abrasive water jets. The water jet method has a lot of benefits and capabilities that makes the process economical. We will bring these cost-cutting skills to use by learning all about Water jet technology. Aside from cost effectiveness, the water jets procedure is widely regarded as the world's greatest flexible and rapidly expanding process. Water jet cutting doesn't use any harmful gases or oils, and it doesn't produce any vapors or risks. It's a very adaptable piece of equipment.

Metal cutting's main goal is to achieve high efficiency while maintaining high product consistency and low machining costs. The treatment choices are largely influenced by the substance's shape and the geometry of a specimen. These two variables usually define the mode of operation, and after that, the operating conditions must be defined. Surface finish is relatively uniform when using traditional machining methods [6]. As a consequence, measuring the superficial roughness at any point on the machine surface is referred to as the machined surface's surface appearance. The technology of abrasive $\mathrm{H} 2 \mathrm{O}$ jet-cutting (AWJC) is relatively recent.

Abrasive $\mathrm{H}_{2} \mathrm{O}$ jets cut has been used in numerous industrial applications due to multiple advantage such as narrow kerf, no heat effects zone in the material, reduced waste disposal costs, low intensity relative to other traditional machining processes, and so on. Despite many benefits over many other methods of traditional manufacturing, there are two main roadblocks to more industrial application: comparatively high machining costs and the creation of striation marks on the material's surface at higher cutting depths [9].

Abrasive water Jet Machining used in many industries and have many advantages over many conventional or drilling operation. Some advantages like low cutting force, large flexibility, mechanical versality is high, and hence high productivity. Abrasive water jet machining uses the concept of erosion mechanism with high pressure water jet and having high speed with abrasive slurry that cuts the target part of materials with help of erosion. The conventional process uses the concept of shearing and friction to cut the part of workpiece. It eliminates the heat affected zones and other expensive cutting tools just like diamonds and others. Today lots of commercial water jet machine available with different sizes and with different pressure available all over the world [11]. 


\section{Abrasive- $\mathrm{H}_{2} \mathrm{O}$-Jet-Machine Set Up}

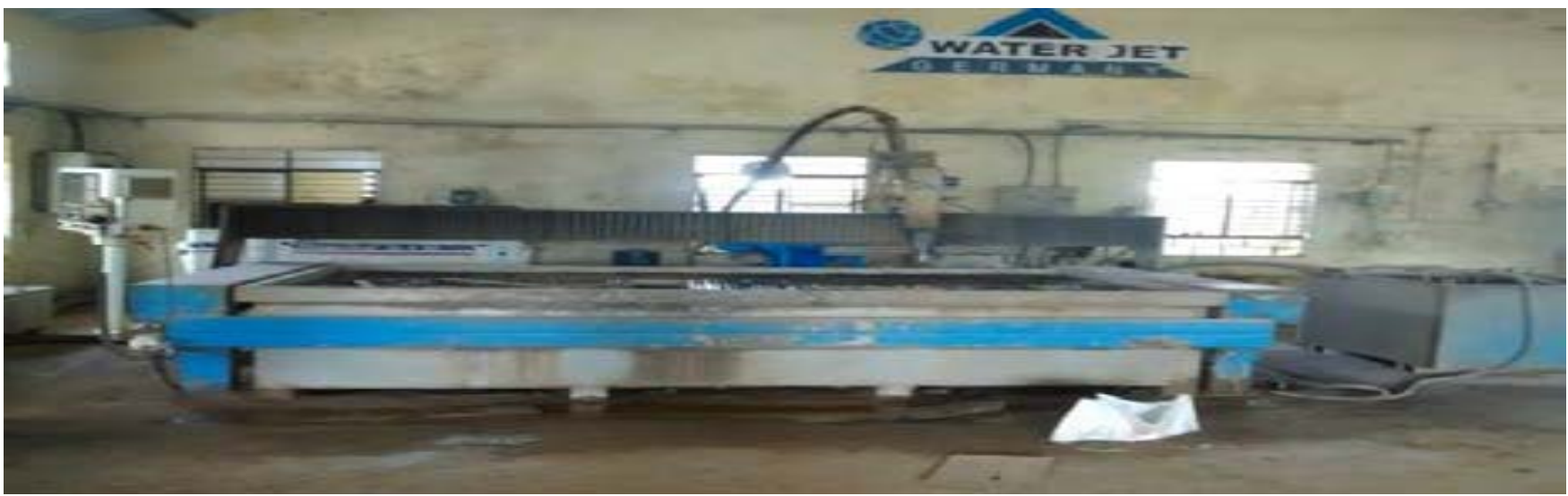

Figure.1. Excels Abrasive $\mathrm{H}_{2} \mathrm{O}$ Jet Machines

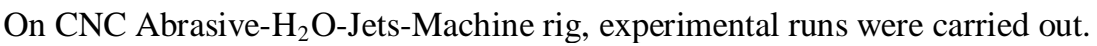

\begin{tabular}{|c|l|l|}
\hline S.No & \multicolumn{1}{|c|}{ Description } & \multicolumn{1}{c|}{ Range } \\
\hline 1 & $\begin{array}{l}\text { Controlling of } \\
\text { Machine }\end{array}$ & CNC \\
\hline 2 & Voltage & $415 \mathrm{~V}$ \\
\hline 3 & Frequency & $50 \mathrm{~Hz}$ \\
\hline 4 & Phases & 3 \\
\hline 5 & Power & $547 \mathrm{~W}$ \\
\hline 6 & Current & $1.8 \mathrm{~A}$ \\
\hline 7 & Table size & $3 *$-axis - \\
& Travel & $\begin{array}{l}\text { XoOOmm, Y-axis } \\
\text { Z-axis }-260 m m\end{array}$ \\
\hline 8 & & $1.1 \mathrm{~mm}$ \\
\hline 9 & Nozzle diameter & Garnet \\
\hline 10 & Abrasive type & $80 \mathrm{Mesh}$ \\
\hline 11 & Abrasive size & $0.35 \mathrm{~mm}$ \\
\hline 12 & Orifice diameter & $8 \mathrm{~mm}$ \\
\hline 13 & $\begin{array}{l}\text { Focusing tube } \\
\text { diameter }\end{array}$ & $3500 \mathrm{bars}$ \\
\hline 14 & Water pressure & 3.5 litre/min \\
\hline 15 & Water flow rate & \\
\hline
\end{tabular}

The specimen was mounted by clamping it to work bench. Orientation point on the specimen was established the work coordinate scheme (WCS). WCS has been used as a guide for the programming.

The job's ground edges acted as a reference point. The cutting procedure is carried out on the work object waterabrasive concoction . Stand-off, abrasive flowrate, and travel speed are all inputs of CNC Abrasive-Water-Jets-Machine.

\section{LITERATURE SURVEY}

Many changes to the fourteen parameters have been made, as well as optimization in procedure parameters for a variety of constituents using abrasive- $\mathrm{H}_{2} \mathrm{O}$-jet machining. A few of them are mentioned farther down.

Puneet Tandon, Divyansh Patel et.al [1]. The thermally-enhanced-abrasive- $\mathrm{H}_{2} \mathrm{O}$-jet-machining (TEAWJM) procedure, which uses an external heat source to boost the manufacturing capability of a conventional abrasive- $\mathrm{H}_{2} \mathrm{O}$-jet device, is investigated. The current work pronounces an observational study of thermally-enhanced-machining (TEM), which requires installing an oxyacetylene gas welding rig as its outside high temperature source to the device arrangement, due to which job is locally heated and the degree of heat is detected with a noncontact-laser-thermometer. Materials that are difficult to machine Mild- 
steel-Inconel-718(MS-A36), Titanium (Ti6Al4V) at critical temperatures that has been Researched on cutting parameters which has provided with absolute factorial DOE. Thermal treatment on exterior morphology of substance machined was investigated in order to measure the technique's efficacy. TEM has been shown to increase the rate of material removal, reduce machining time, and reduce power usage.

John A. Webster [2]. The space industry is expanding rapidly over the years, with closely 30,000 new profitable passenger planes estimated is needed by 2030 to light rising global demand. Abrasive manufacturing is a popular substance subtraction method used for construction in aviation machineries. Industrial exercise at the moment General work-piece integrity standards of surface, wheel preparation solutions, fluid distribution systems, and machine tool designs are all discussed in terms of grinding in aviation industry. Research on composites, machinability of aviation alloys, and recent advances including innovative grinding methods, was critically reviewed.

B.Satyanarayana, G.Srikar [6]. One of the flexible machining processes of hard-to-machine and rough materials is Abrasive$\mathrm{H}_{2} \mathrm{O}$-Jet-Machining. Aim of the paper stands to use AWJM method on INCONEL 718 to optimize kerf width while also reducing material subtraction rate. The procedure parameters chosen are the abrasive flow rate, standoff distance, and strain. Taguchi Grey analysis is used Due to the use of multi-response optimization. Title study has been written on makes It clear from the Literature survey that. material used in aviation, chemical refining, and regenerative medicine is Inconel-825 (Nickel Iron \& Chromium based alloy). Design-of-Experiments (DOE) is built in Mini-Tab Computer software using Taguchi to optimize constraints such as flow rate of Abrasive, Transverse direction, and Standoff distance. After processing, such process constraints will be calibrated using ANOVA and Grey Taguchi Technique on basis of Minimum-Surface-Roughness, Maximum MRR, and Minimum Kerf Width (4-15).

\section{III.OBJECTIVE AND METHODOLOGY}

A. A hydraulic pump is used to transport Water from a tank to intensifier. Using an intensifier Water at high pressure is pumped at around 2000-4000 bar. The potential-energy of the water is converted to kinetic energy as it is sprayed at such a high pressure through a $0.2-0.4 \mathrm{~mm}$ diameter orifice, resulting in a $1000 \mathrm{~m} / \mathrm{s}$ jet. The surfaces are sliced to the surface as the high-velocity water jet leaves the nozzle. necessary amount[26,27].

B. Thesis Experiments are performed to assess the result, of procedure parameters on ideal situation, using Taguchi's theorem. To assess the right conditions, a series of experiments are performed. Method parameter optimization is expected. Experiment to conform the desired degree of Process parameter forecast are conducted.

\section{WORKING PRINCIPLE OF ABRASIVE WATER JET MACHININGS}

Users can use the water purification and storage system to supply pressure up to ultrahigh pressure. In a standard AWJ system, there are two holding tanks: one for cutting water and the other for cooling water. Particles larger than $1 \mathrm{~m}$ in size should generally be withdrawn from the water because they cause wear on the pump's vital parts, resulting in pump failure. The temperature of the oil pump is lowered by using cooling water. System for generating high pressure, includes an intensifier and an accumulator for high pressure storage as well as generation, respectively. The intensifier has a doubleacting reciprocating pump that runs on oil pressure. There are 2 kinds in ultrahigh-pressure-pumps

\section{Design of Experiment-DOE}

The experiment is planned such that enough evidence is gathered and mathematical techniques are used to interpret it, resulting in accurate and objective results. The method of measurement is related to the experiment architecture. researchers have found that there is a major impact on Response parameter from AWJM parameters. Process parameters that are under consideration are Standoff width, traverse rate, impact angle, passes number, abrasive-content, abrasive-particle-size, abrasive-mass-flow-rate, as well as abrasive shape, focusing tube length and diameter, and water pressure. Dimensions of the orifice, etc. In this paper, we examined the effects of parameters such as Travel-speed ( $\mathrm{mm} / \mathrm{min})$, Flow Rate of Abrasive (gm/min), and Standoff(mm) on MRR (gm/min), Kerf thickness(mm), and Surface Roughness(m).

A variety of techniques and modes of machining operations are used to create machine parts and semi-finished goods. Accuracy casting, plastic shaping (die-grinding, cross-wedge-rolling) [1,] and high-speed machining (roughing, finishing, accuracy-cutting) [2-4] are all examples of cutting-edge machining methods used in 21st-century production. 
one highly-growing industrial machineries is Abrasive- $\mathrm{H}_{2} \mathrm{O}$-jet machining (AWJM), and it's progressively being used to prepare materials for further production. The expressions abrasive-H2O-jet machining (AWJM), abrasive-H2O-jet cutting (AWJC), and abrasive-water-jet technology have all been suggested (AWJT). AWJM is a non-traditional technique which is better than any other cutting processes for shaping different forms in structural materials, and in variety of ways.

Its benefits include a high degree of flexibility in terms of the substance being sliced-it can cut almost any non-metal or metal layer excluding diamond. AWJ technology enables light alloys to be machined twice as quickly as steel. AWJ also slices into a wide variety of thicknesses of aluminum alloys, ranging from slim sheets (under $3 \mathrm{~mm}$ ) to dense plates (over $150 \mathrm{~mm}$ ). cuts are smooth and have a decent finish, so they seldom need additional finishing. High pressure AWJM is constantly evolving, allowing for greater efficiency and broader range of applications.

The advantages of abrasive waterjet technology over traditional machining methods are bolstered by its other advantages $[5,7]$. The technology can effortlessly fold complex geometries and can machining materials of any hardness. Characteristics of AWJ are beyond a doubt the most significant indicators of its handling capability soft alloys, $\mathrm{Mg}$ or $\mathrm{Al}$ [5] are: During machining, there are not any thermal impacts, insignificant cutting-forces (decreased heat creation and no requirement of unique high-tech gear), and nontoxic gases. Water pressure is a parameter that controls the form of water jet while cutting; as the pressure rises, so does the water jet stream and aerodynamic power. The waterjet's central zone is reduced, and the jet escape angle is increased. depth of cut is affected by the jet geometry; when conical, increasing the standoff gap reduces depth of cut. Jet deflection also happens where the thickness of a workpiece is surpassed. Machining accuracy is deeply influenced mostly by cut depth. if jet effect deepness increases, the cut excellence degrades.

This may be clarified by the abrasive medium's kinetic energy being distributed unevenly (the majority of the energy is expended scraping the upper sheet of the specimen, and residual force is not sufficient in produce the cut properly). As consequence, machining on the cut's lower side tends to produce visible striations.

efficiency, workpiece surface quality, technical criteria, or, respectively, to characterise and calculate output efficacy, a mixture of the amount of labour and the result of the job is used.

In the aviation industry, considerations such as proper part construction, machine-tool-workpiece-system rigidity, optimum technical machining parameters, and high-durability tooling, that guarantees high efficiency, and sufficient constancy are crucial for output efficiency.

Chief target of the efficiency-oriented survey, is finding consequence of numerous manufacturing conditions on finished product geometry and material removal rate. Researchers usually assume the consequence of feed-rate and standoff on surface consistency.

The most extensively studied use of abrasive- $\mathrm{H}_{2} \mathrm{O}$-jet technology is in the manufacturing of aluminium alloys. Range of $\mathrm{Al}$ alloys investigated in scientific studies is very wide, ranging from approximately unadulterated aluminium alloys (1xxx series) [11,12] to Al-Mg alloys (5xxx series) [11,13,14], Al-Mg-Si alloys (6xxx series) [11,15-22], and Al-Zn-Mg alloys (7xxx series) $[11,23,24]$.

Table 1. summarizes all chosen cited analysis.

\begin{tabular}{|c|c|}
\hline Materialla & Masthinimb Clonditions \\
\hline 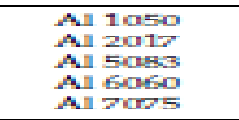 & 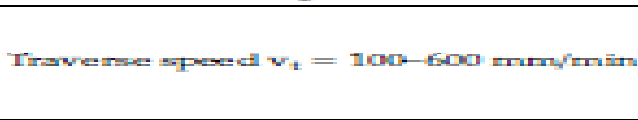 \\
\hline A II 1 DÉ & 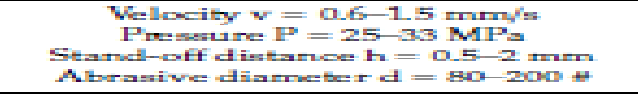 \\
\hline A. $5 \mathrm{DSB}-\mathbb{1}-132$ & 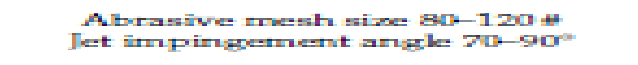 \\
\hline A I GOEO & 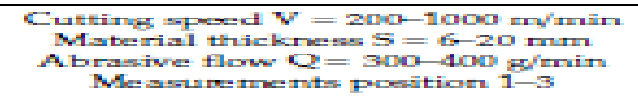 \\
\hline A. EOE1-TE & 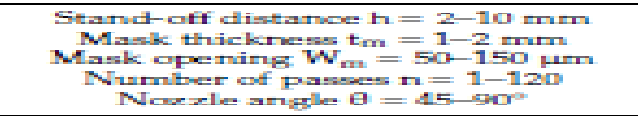 \\
\hline Al Gougl Thesi. & 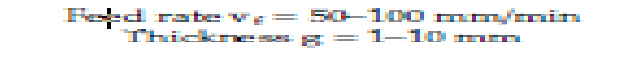 \\
\hline Al Enati mesi. & Cutting movelhoul \\
\hline Al tora-Tí & 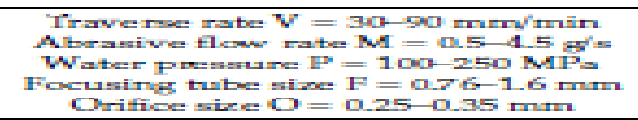 \\
\hline
\end{tabular}




\section{MATERIALS AND METHODS}

The consistency and process reliability of AWJM of Si-enhanced Al-alloys AlSi10Mg and AlSi21CuNi is an important part of this work. The test flow diagram, the AWJ cut visualization, and the neural-net prognostic model are all seen within Figure 1. This analytical methods and methodology used during the investigations is strictly adhered to a global bar, PN-EN ISO 9013. The adjustable operating conditions were also the flowrate of abrasive ma, jet-feed rate vf, also specimenlength(paraproduct). An OPALWATERJET COMBO plasma and waterjet cutting device from Legnica, Poland, was used for the Al-Si alloy cutting process. AlSi10Mg 60mm, 46/23/12mm, $270 \mathrm{~mm}$, and AlSi21CuMn 60mm, 46/23/12mm, $154 \mathrm{~mm}$ were used to make the specimens. The abrasive-medium was GARNET 80mesh, a extensively used blasting-abrasive with small dustiness, small wear, and increased hardness, and sharp-edged elements that have decent machinability properties [5]. Continuous AWJ cutting parameters are seen.

Table 2. AWJ cutting with constant technical parameters

\begin{tabular}{cc}
\hline Nozzle (focusing tube) diameter- $\mathrm{d}_{\mathrm{o}}$ & $0.7(\mathrm{~mm})$ \\
Abrasive (size) & Garnet $80 \mathrm{mesh}$ \\
Standoff distance & $3(\mathrm{~mm})$ \\
Nozzle width & $60(\mathrm{~mm})$ \\
Water pressure-p & $350(\mathrm{MPa})$ \\
\hline
\end{tabular}

Table 3. shows the different cutting criteria that were put to the test during AWJ machining. These were pre-determined, including the constant parameters, based on prior studies and literature.

\begin{tabular}{cccc}
\hline Workpiece & $\begin{array}{c}\text { Sample Height h } \\
(\mathbf{m m})\end{array}$ & $\begin{array}{c}\text { Abrasive Flow Rate } \\
\mathbf{m}_{\mathbf{a}}(\mathrm{g} / \mathrm{min})\end{array}$ & $\begin{array}{c}\text { Jet Feed Rate } \\
\mathbf{v}_{\mathbf{f}}(\mathbf{m m} / \mathbf{m i n})\end{array}$ \\
\hline \multirow{2}{*}{ ALSi10Mg } & 46 & & \\
& 23 & & \\
& 12 & $500(\mathrm{~g} / \mathrm{min})$ i.e, $-100 \%$ & $5-100$ \\
AlSi21CuNi & 46 & $250(\mathrm{~g} / \mathrm{min})$ i.e., $-50 \%$ & \\
& 23 & & \\
\hline
\end{tabular}

\section{Grey-Taguchi-Technique}

In the direction of determining the implication of process variables such as Metallic Removal Rate, Kerf Width, and Exterior Finish. ANOVA is used to analyse the data. Table 6 shows the ANOVA table for the Grey relational grade. The most influential metric is transverse speed, which accounts for 48.39 percent of the contribution to grey relational grade, accompanied by Flow Rate of Abrasive and Standoff.

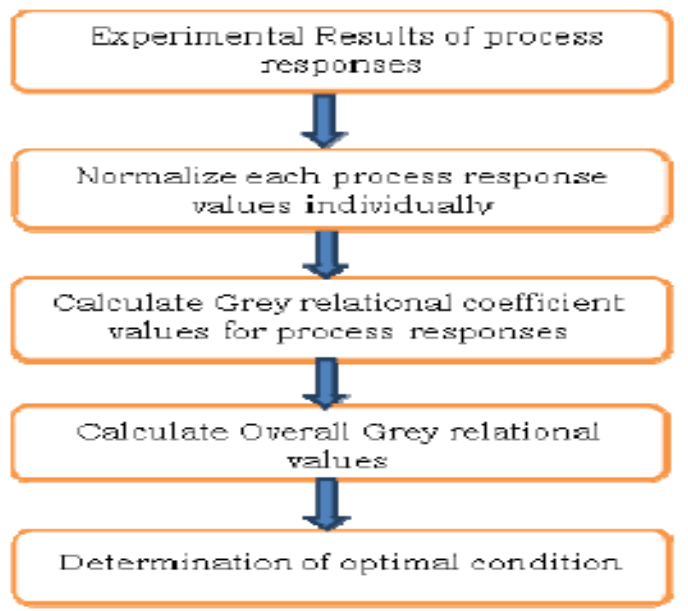

Figure 2. Flow Chart represents the Grey Taguchi Technique 


\section{CONCLUSION}

A wide range of procedure parameters in the abrasive- $\mathrm{H}_{2} \mathrm{O}$-jet machining process influence the cutting surface consistency. In abrasive- $\mathrm{H}_{2} \mathrm{O}$-jet machining, procedure parameters including the hydraulic-power, travel-speed, standoff, flowrate of abrasive mass, abrasive constituents, nozzle dimension and diameter, orifice diameter, abrasive form, scale, and resistant to pressure have a lesser or greater impact on cutting performance. Cutting surface characteristics such as surface raggedness, surface waviness, substance removal rate, kerf top width, kerf bottom width, and kerf taper angle are all measured. It stood deduced from the literature. (i) Hydraulic force per unit area (MPa) and abrasive material type were the two nearly critical regulating factors that determine surface raggedness and taper ratio, correspondingly. (ii) Content removal rates are lower while traverse speeds are high. (iii) Garnet abrasives, accompanied by Al2O3, create a greater taper of cut. This is attributed to Al2O3's higher hardness than garnet.

\section{REFERENCES}

[1] D. Patel, P. Tandon“CIRP Journal of Manufacturing Science and Technology”, ISSN: 1755-5817, September 102015.

[2] N. Tamannaee, J.K. Spelt, M. Papini,” Abrasive slurry jet micro-machining of edges, planar area sand transition slopes in a talc-filled copolymer”, Precision Engineering, Department of Mechanical and Industrial Engineering, University of Toronto, Department of Mechanical and Industrial Engineering, Ryerson University, Toronto, Canada, Issue 24, June 2015. 19

[3] Fritz K locke, Sein Leung Soo, Bernhard Karpuschewski, John A.Webster, Donka Novovic, Amr Elfizy, Dragos A. Axinte, Stefan Tönissen,” Abrasive machining of advanced aerospace alloys and composites”,CIRP Annals - Manufacturing Technology, Volume 64,Issue 2, May 2015.

[4] Fang-Jung Shiou, Assefa Asmare,” Parameter's optimization on Surface roughness improvement of Zerodur optical glass using an Innovative rotary abrasive fluid multi-jet polishing process”, Precision Engineering,Department of Mechanical Engineering, National Taiwan University of Science and Technology, Taiwan,Issue 17, April 2015.

[5] Derzija Begic- Hajdarevic, Ahmet Cekic, Muhamed Mehmedovic, Almina Djelmic“Experimental Study on Surface Roughness in Abrasive Water Jet Cutting” 25th DAAAM International Symposium on Intelligent Manufacturing and Automation, ISSN: 1877-7058, 2015.

[6] B. Satyanarayana, G. Srikar," Optimization of abrasive water jet machining process parameters using Taguchi Grey RelationalAnalysis(TGRA)”, Proceedings of 13th IRF International Conference, Pune , India, ISBN:978-93-84209-37-[7], Issue 20,July 2014. 7. Lorincz, J.Waterjets-evolving from macro to micro. Manuf. Eng. 2009, 143, 47-53.

[8]. Skoczylas, A. Analiza porównawcza procesu cie cia wia zka laserowa i i strumieniem wodno-s'ciernym. J. Adv.Sci. Technol. 2011, 8, 121-128.

[9]. Manu, R.; Babu, N.R. Influence of jet impact angle on part geometry in abrasive waterjet turning of aluminium alloys. Int. J. Mach. Mach. Mater. 2008, 3, 120-132. [CrossRef]

[10]. Kolohan, E.; Khajavi, A.H. Modeling and optimalization of abrasive waterjet parameters using regression analysis. Int. J. Sci. 2009, 3, $1425-1430$.

[11].Klichova, D.; Klich, J. Study of the material machinability on quality of surface created by abrasive water jet. Procedia Eng. 2016, 149, 177-182. [CrossRef]

[12]. Xu, Q.W.; Qiang, C.H.; Guo, C.W. Experimental study on the surface roughness of 1060 aluminum alloy cut by abrasive water jet. Mater. Sci. Forum 2019, 950, 32-37. [CrossRef]

[13]. Selvakumar, G.; Prakash, S.S.R.; Lenin, N. Experimental study on abrasive water jet machining of AA5083 in a range of thicknesses. Int. J. Abras. Technol. 2018, 8, 218-231. [CrossRef]

[14]. Yuvaraj, N.; Kumar, M.P. Cutting of aluminium alloy with abrasive water jet and cryogenic assisted abrasive water jet: A comparative study of the surface integrity approach. Wear 2016, 18-32. [CrossRef]

[15]. C' ojbašic', Ž.; Petkovic', D.; Shamshirband, S.; Tong, C.W.; Chong, W.T.; Jankovic', P.; Duc`ic', N.; Baralic', J. Surface roughness prediction by extreme learning machine constructed with abrasive water jet. Precis. Eng. 2016, 43, 86-92. [CrossRef]

[16]. Mokhtar, N.; Gebremariam, M.; Zohari, H.; Azhari, A. Analysis of acoustic emission during abrasive waterjet machining of sheet metals. IOP Conf. Ser. Mater. Sci. Eng. 2018, 342, 6. [CrossRef]

[17]. Haghbin, N.; Ahmadzadeh, F.; Papini, M. Masked micro-channel machining in aluminum alloy and borosilicate glass using abrasive water jet micro-machining. J. Manuf. Process. 2018, 35, 307-316. [CrossRef]

[18]. Herghelegiu, E.; Radu, M.C.; Schnakovszky, C.; Tampu, C.N. Considerations on material thickness influence on the AWJ processing quality of an aluminium alloy. MATEC Web Conf. 2017, 94, 03007. [CrossRef]

[19]. Zhao,W.; Guo, C. Topography and microstructure of the cutting surface machined with abrasive waterjet. Int. J. Adv. Manuf. Technol. 2014, 73, 941-947. [CrossRef]

[20]. Radu, C.; Herghelegiu, E.; Schnakovszky, C. Comparative study on the three unconventional cutting technologies on cut surface quality. Indian J. Eng. Mater. Sci. 2005, 22, 127-132. 
[21]. Jegaraj, J.J.R.; Babu, N.R. A soft computing approach for controlling the quality of cut with abrasive waterjet cutting system experiencing orifice and focusing tube wear. J. Mater. Process. Technol. 2007, 185, 217-227. [CrossRef]

[22]. Maros, Z. Taper of cut at abrasive waterjet cutting of an aluminium alloy. Prod. Process. Syst. 2012, 5, 55-60.

[23]. Ahmed, T.M.; Elmesalamy, A.; Youssef, A.; El Midany, T.T. Improving surface roughness of abrasive waterjet cutting process by using statistical modeling. CIRP J. Manuf. Sci. Technol. 2018, 22, 30-36. [CrossRef]

[24]. Boud, F.; Loo, L.; Kinnell, P. The Impact of plain waterjet machining on the surface integrity of aluminium 7475 . Procedia CIRP 2014, 13, 382-386. [CrossRef]

[25]. Begic-Hajdarevic, D.; Cekic, A.; Mehmedovic, M.; Djelmic, A. Experimental study on surface roughness in abrasive water jet cutting. Procedia Eng. 2015, 100, 394-399. [crossref]

[26]. JHA, K. K., ARORA, R., \& PABLA, B. CONDITION MONITORING OF LUBRICATING OIL USING INTERNET OF THINGS (iot).2020,10,3,9878.

[27]. Kumar Jha, K., \& Pabla, B. S. A Real Time Engine Oil Monitoring System for Diagnosis of Lubricant using IoT Network 2020,9,8,123-136.

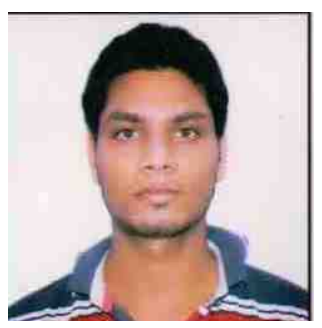

Nikhil Rai is M. Tech Scholar in Department of Mechanical Engineering, KCCITM Gr Noida, UP, India. He did B. Tech in Mechanical Engineering from KCC Institute of Technology and Management, Gr Noida, UP, India.

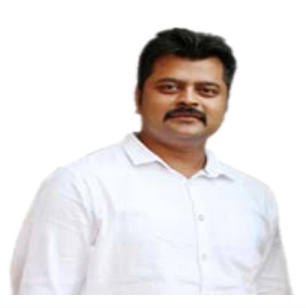

Mr. Keshav Kumar Jha is Assistant Professor in Department of Mechanical Engineering, KCC Institute of Technology and Management Greater Noida, UP. He is also working as Associate Dean of Student welfare. Area of specialization manufacturing, tribology, IoT, Sensor. Currently member of SAE India, IAENG 